\title{
Análisis de las Páginas Web de los Centros Públicos de Educación Secundaria de Cantabria (España)
}

\author{
Analysis of the Websites of Public Secondary Schools of \\ Cantabria (Spain)
}

\author{
Víctor Tardío-Crespo * \\ Carmen Álvarez-Álvarez \\ Universidad de Cantabria, España
}

\begin{abstract}
Con la profunda transformación social que ha provocado la integración de las TIC en nuestro día a día, los modos de comunicación en el mundo educativo han evolucionado hacia internet y hacia un universo en red. Este hecho ha convertido a las páginas web de los centros educativos, entre otros elementos, en herramientas catalizadoras del panorama escolar. Con la finalidad de conocer la presentación de los contenidos de dichas páginas ante sus diferentes públicos se ha llevado a cabo en el presente trabajo una investigación para analizar las sedes web de los cuarenta y ocho centros públicos de Educación Secundaria de la Comunidad Autónoma de Cantabria. El análisis se ha llevado a cabo en relación a su contenido, organización, navegación, apariencia, diferenciación, velocidad, utilidad y accesibilidad. Los resultados obtenidos revelan cifras realmente alentadoras, como que sólo un 27’08\% y $14,58 \%$ muestran deficiencias en su organización y claridad. Cabe destacar por otro lado, que la nota media de los sitios web en utilidad para las partes interesadas es de un 8'19 de valoración en su conjunto. Nos encontramos en líneas generales ante sitios webs con un claro carácter progresivo, activo e interactivo, aunque es posible concluir sugiriendo algunas mejoras como facilitar una difusión más rica de recursos útiles, así como suministrar una mayor exposición de los planes y proyectos más importantes del centro en algún apartado de las páginas web de los centros educativos.
\end{abstract}

Descriptores: TIC; Marketing; Escuela; Comunidad; Información.

\begin{abstract}
With the profound social transformation that has led to the integration of ICT in our day to day, modes of communication in the educational world have evolved towards the Internet and towards a networked universe. This fact has turned the web pages of educational centers, among other elements, into catalytic tools for the school panorama. In order to know the presentation of the contents of these pages to their different audiences a research has been carried out in the present work to analyze the web sites of the forty-eight public secondary education centers of the Autonomous Community of Cantabria. The analysis has been carried out in relation to its content, organization, navigation, appearance, differentiation, speed, utility and accessibility. The results obtained reveal really encouraging figures, such as that only $27^{\prime} \mathrm{O} 8 \%$ and $14{ }^{\prime} 58 \%$ show deficiencies in their organization and clarity. It should be noted on the other hand, that the average score of the websites in utility for the interested parties is of an 8'19 valuation as a whole. We are generally in front of websites with a clear progressive, active and interactive character, although it is possible to conclude by suggesting some improvements such as facilitating a richer dissemination of useful resources, as well as providing a greater exposure of the most important plans and projects of the center in some section of the web pages of educational centers.
\end{abstract}

Keywords: ICT; Marketing; Schools; Communities; Information.

*Contacto: vtardiocrespo@gmail.com

ISSN: 1696-4713

www.rinace.net/reice/

revistas.uam.es/reice
Recibido: $\quad 2$ de febrero 2018

$1^{\text {a }}$ Evaluación: 13 de abril 2018

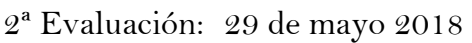

Aceptado: $\quad 3$ de junio 2018 


\section{Fundamentación teórica}

Gracias a la irrupción de las TIC, la confluencia de la Sociedad de la InformaciónComunicación y la Sociedad de la Imagen la humanidad vive por y para la imagen y la información. El motor de este engranaje es Internet (Castells, 2006). A medida que la World Wide Web se vuelve más accesible y universal, es casi de obligado cumplimiento que las organizaciones, entidades, organismos e instituciones tengan su propia página web. De ahí que los centros educativos utilicen cada vez más la página web como soporte de presentación y comunicación con sus audiencias y se enfrenten al reto de difundir su trabajo en la red, informando, orientando y saciando la curiosidad de su público (Álvarez, 2017; Álvarez y García, 2017; Méndez y García, 2016).

La web escolar como portal institucional ha de dirigirse tanto a las audiencias internas (personal del centro, familias y alumnado), como a las externas (profesionales potenciales y sociedad en general). Es necesario que las webs escolares interactúen y desplieguen información de interés para las partes interesadas en cualquier momento y lugar (los estudiantes, el personal de centro, los padres y la comunidad) (Álvarez y García, 2017; Du Preez, 2007; Ferrer, 2005; Lynch, Horton y Marcotte, 2016; Regan, 2003; Taddeo y Barnes, 2016). De hecho, uno de los propósitos del sitio web es transformarse en un elemento de querencia entre sus audiencias (Du Preez, 2007; Hartshorne et al., 2006, 2008; Lynch, Horton y Marcotte, 2016; Maddux, 2001; Peña et al., 2016; Taddeo y Barnes, 2016).

Más concretamente, los objetivos para una web escolar eficiente para los centros educativos han de guiarse por los criterios abordados en los estudios internacionales (Associates, Jacob y Jensen, 2012; Bodura et al., 2009; Hartshorne et al., 2006, 2008):

- Introducción al centro: permitir introducirse en el trabajo del centro educativo cualquiera que sea su nivel.

- Suministro de una fuente de datos útiles: proporcionar datos localmente relevantes.

- Publicación del trabajo del estudiante: proporcionar oportunidades para que los estudiantes publiquen su trabajo tanto a nivel local como global.

- Intermediación hacia la amplitud de la información: facilitar recursos diversos para estudiantes (como herramientas para el estudio de las materias), familias (como información sobre los proyectos educativos, la organización del centro, las asociaciones de padres) y profesorado (como planes institucionales y recursos).

Según la investigación internacional, sintetizamos en ocho las dimensiones específicas que un sitio web escolar ha de tener (Du Preez, 2007; Ferrer, 2005; Hartshorne et al., 2006, 2008; Ng, Parette y Sterrett, 2003; Romero et al., 2002): contenido, organización, navegación, apariencia, diferenciación, velocidad, accesibilidad y utilidad.

a) Contenido: informaciones relevantes de la institución tales como datos sobre su dirección y situación, vías de contacto, documentos administrativos, metas del centro, elementos académicos, galería de fotografías, etc. (Ferrer, 2005). Estos elementos que han de ser útiles para convertir al sitio web en un lugar eficiente. En este sentido, las mejores páginas webs tienen una apariencia simple e intuitiva (Camps et al., 2015; Ng et al., 2003; Poock, 2005). 
b) Organización: la información de la web tiene que estar dispuesta claramente, respondiendo a un diseño funcional orientado al público visitante ( $\mathrm{Ng}$ et al., 2003). Tiene que ofrecer un menú, un directorio o un mapa de navegación organizado siguiendo una lógica (Du Preez, 2007; Ng et al., 2003; Romero et al., 2002). Una organización simplificada hace que sea más fácil encontrar materiales en el sitio y que los diseños parezcan más brillantes y más sugerentes (Regan, 2003).

c) Navegación: la manejabilidad de la web debe ser fácil, predecible, consistente y atractiva para convertir en eficaz y eficiente la información que soporta la página web (Du Preez, 2007; Ng et al., 2003 Oyola, 2016; Regan, 2003). Existe una regla de oro básica: dar la máxima información posible con el menor número de clicks (los expertos hablan de hasta tres) (Camps et al., 2015; Maddux, 2001; Ng et al., 2003; Regan, 2003).

d) Apariencia: la imagen produce en el visitante atracción o rechazo hacia la página (Du Preez, 2007; Regan, 2003; Ng et al., 2003). Cuidar la apariencia significa tener en consideración aspectos de diseño como la legibilidad de la información (tamaño, contraste de colores, justificación), la función de cada uno de los elementos (imágenes, sonidos, texto, gráficos), así como, otras cuestiones más técnicas (calidad de diseño, tiempo de carga y ejecución, requisitos mínimos del sistema, servicios técnicos y de apoyo, coherencia visual, etc.) (Camps et al., 2015; Cantabria, 2009; Du Preez, 2007; Ferrer, 2005; Hartshorne et al., 2006, 2008; Romero et al., 2002).

e) Diferenciación: cada página web ha de buscar su singularidad, posicionarse y distinguirse del resto a través de un desarrollo inteligente de los contenidos, de un diseño gráfico aceptable, una programación adecuada, una promoción de la página y un mantenimiento continuo (Du Preez, 2007). Tubin y Klein (2007) proponen que los sitios webs escolares formen parte del plan estratégico de la escuela para así poder presentar sus logros, impulsar su posicionamiento y mejorar su reputación, sin enmascarar ni distraer de la verdadera misión del centro y del tejido pedagógico de la enseñanza que se produce dentro de ella. A raíz de este pensamiento, los responsables de los centros escolares han comenzado a nutrirse del mundo del marketing, de sus herramientas y de sus técnicas para llevarlas al terreno escolar. El marketing se observa, en los discursos y vocabulario empleados en las metas, la misión, la visión, los objetivos o filosofía que algunos centros exponen en sus sitios webs; o del empleo de imágenes con finalidad de escaparate ante los padres y la comunidad educativa (Smith, 2007; Tamatea, Hardy y Ninnes, 2008; Yemini y Cohen, 2016; Wilson y Carlsen, 2016).

f) Velocidad: se recomienda que las páginas sean pequeñas para que éstas sean rápidas, ya que los usuarios tendrán una amplia variedad de equipos, distinta velocidad de conexión y grado de paciencia (Ng et al., 2003; Regan, 2003). La velocidad depende de la incorporación de imágenes y gráficos en los sitios webs escolares. Estos han de ser de calidad, pero de manera que no impida la carga de la página ni entorpezca la velocidad de descarga, debiendo evitarse la incorporación de demasiados gráficos o imágenes grandes e innecesarias (Hartshorne et al., 2006, 2008; Maddux, 2001; $\mathrm{Ng}$ et al., 2003).

g) Accesibilidad: todas las personas, independientemente de sus discapacidades, deben poder disfrutar de la información desde una condición de igualdad (Krach y Jelenic, 2009; Maddux, 2001; Oyola, 2016; Rodríguez et al., 2013; Stilz y Menter, 2009; 
Wells y Barron, 2006). Para ello, se deben seguir las "Pautas de Accesibilidad al contenido Web (WCAG 2.0)" de la "Iniciativa de Accesibilidad a la Web, el World Wide Web Consortium (W3C)".

h) Utilidad: existe un acuerdo común en reconocer el potencial de los sitios webs escolares como una herramienta didáctica para docentes, estudiantes y familias (Aguilar y Leiva, 2012; Careaga, Jiménez y Badilla, 2014; Romero et al., 2002;). Hay que fomentar en la medida de lo posible la integración de material útil para los diferentes agentes (Tubin y Klein, 2007), y el uso de plataformas de enseñanzaaprendizaje (Moreira, Reis-Monteiro y Machado, 2017). Hay que alentar al profesorado y a los centros a cargar sus planes y proyectos. Asimismo, los estudiantes también deben participar en la creación de contenido para que tengan un sentido de pertenencia y desarrollen habilidades TIC (Hu y Soong, 2007).

Además de lo anterior, algunos autores nos hablan de otras dimensiones. Oyola (2016) recomienda evaluar periódicamente los sitios webs valorando aspectos como la funcionalidad, la usabilidad, la portabilidad y la eficiencia. Esto supone ver si lo que hay es lo que se necesita y si es efectivo (Du Preez, 2007; Romero et al., 2002; Taddeo y Barnes, 2016). Por otra parte, se recomienda actualizar los contenidos semanalmente para no caer en la obsolescencia, ya que los usuarios necesitan siempre nuevos contenidos (Du Preez, 2007; Romero et al., 2002). Asimismo, la figura del coordinador TIC, como persona encargada de dinamizar la web y al equipo docente encargada de su implementación y seguimiento es fundamental (Balas, Mirea y Mirea, 2014; McGarr y McDonagh, 2013; Rodríguez, Pozuelos y León, 2014).

Sin embargo, son necesarios estudios que analicen el estado de las webs escolares para saber realmente en qué punto del desarrollo web nos encontramos y determinar hacia dónde avanzar.

\section{Método}

El objetivo de este estudio es analizar el estado actual de las páginas web escolares de un conjunto de centros para saber en qué punto del desarrollo web nos encontramos y realizar propuestas de mejora. Los objetivos específicos de este estudio guardan relación con el análisis exploratorio de cada uno de los ocho rasgos específicos fundamentales anteriormente definidos, ya que hay bastante consenso sobre el tema entre los autores expertos. Tras visitar de manera irregular algunas páginas web escolares partimos de la hipótesis de que las páginas web escolares cumplen una función informativa sobre todo y que podrían orientarse más y mejor a sus visitantes.

Para realizar este estudio hemos decidido: 1) realizar un estudio con el universo de los centros públicos existentes en nuestra comunidad, lo cual permitiese una visita profunda de cada página $\mathrm{y}$, asimismo, ofrecer informaciones relevantes y en buena medida, extrapolables a otras regiones. 2) Centrar el estudio en la etapa Secundaria, ya que es una etapa en la que hay una gran diversidad de opciones curriculares (aspecto que no tienen la etapa Infantil y Primaria) y puede haber profesorado especializado en materia TIC que contribuya al desarrollo web. En base a estos dos criterios visitamos y analizamos las sedes web de los 48 Institutos de Educación Secundaria (IES) públicos de Cantabria. Se trata de 19 centros rurales, 17 urbanos y 12 neourbanos. 
Para realizar este estudio exploratorio hemos tomado como referencia el portal institucional "EduCantabria" en el que la Consejería de Educación de Cantabria ofrece alojamiento a todas las sedes web de los centros de la región (Cantabria, 2009). No obstante, algunos IES no han optado por esta vía y emplean preferentemente sus dominios privados para sus sitios web (el 66,67\%). Cuando así es, hemos analizado estas páginas web privadas y no la de Educantabria, ya que son las que se encuentran más completas y actualizadas. Por su parte, el 33'33\% utilizan su web del portal Educantabria como sede principal. Como curiosidad, señalar que El 27,08\% únicamente tienen su página en Educantabria; el 4'17\% sólo sede web propia; y el 68'75\% tienen ambas opciones.

Para realizar el análisis hemos empleado Excel, siguiendo el siguiente esquema de análisis planteado en la tabla y según las dimensiones planteadas en el marco teórico (cuadro 1).

Cuadro 1. Dimensiones, variables y su definición

\begin{tabular}{|c|c|c|}
\hline DIMENSIÓN & VARIABLES & DEFINICIÓN \\
\hline \multirow{31}{*}{ Contenido } & \multirow{4}{*}{ Datos de contacto } & Correo: sí/ no/ incompleto \\
\hline & & Dirección: sí/ no/ incompleto \\
\hline & & Teléfono: sí/ no/ incompleto \\
\hline & & $\begin{array}{l}\text { Redes sociales-blogs: sí/ no/ cuáles/ blogs } \\
\text { activos-inactivos }\end{array}$ \\
\hline & \multirow{4}{*}{ Galería de fotos } & Instalaciones: sí/ no \\
\hline & & Día a día: sí/ no \\
\hline & & Excursiones: sí/ no \\
\hline & & Otras actividades y/o eventos: sí/ no \\
\hline & \multirow{2}{*}{ Historia/ metas $^{1}$} & Historia: de 0 a 3 \\
\hline & & Metas: de o a 3 \\
\hline & \multirow{4}{*}{ Documentos administrativos } & Comunicados/ avisos: sí/ no/ incompleto \\
\hline & & Impresos: sí/ no/ incompleto \\
\hline & & $\begin{array}{l}\text { Horarios secretaría/ conserjería: sí/ no/ } \\
\text { incompleto }\end{array}$ \\
\hline & & Matrícula: sí/ no/ incompleto \\
\hline & \multirow{3}{*}{ Información de interés } & AMPA: sí/ no/ qué información \\
\hline & & Transportes: sí/ no/ qué información \\
\hline & & $\begin{array}{l}\text { Otra información (local, global, tiempo...): } \\
\text { sí/ no/ qué información }\end{array}$ \\
\hline & \multirow{4}{*}{ Proyectos y planes $^{2}$} & PEC: de 0 a 3 \\
\hline & & PGA: de 0 a 3 \\
\hline & & NOFC: de 0 a 3 \\
\hline & & Otros: sí/ no/ cuál o cuáles \\
\hline & \multirow{3}{*}{$\begin{array}{l}\text { Enseñanzas-profesorado- } \\
\text { departamentos }\end{array}$} & Enseñanzas: sí/ no \\
\hline & & Profesorado: sí/ no \\
\hline & & Departamentos: sí/ no \\
\hline & \multirow{6}{*}{ Servicios y actividades } & Horario centro: sí/ no \\
\hline & & Horario clases: sí/ no \\
\hline & & Calendario escolar: sí/ no \\
\hline & & Biblioteca: sí/ no \\
\hline & & Noticias: sí/ no \\
\hline & & Actividades: sí/ no \\
\hline & Actualización & Sí/ no/ aparentemente \\
\hline \multirow{2}{*}{$\begin{array}{l}\text { Organización } \\
\text { y navegación }\end{array}$} & \multirow{2}{*}{ Botoneras } & Botonera vertical: sí/ no \\
\hline & & Botonera horizontal: sí/ no \\
\hline
\end{tabular}




\begin{tabular}{|c|c|c|}
\hline & Estructura web & Mapa web: sí/ no \\
\hline & Links & Enlaces directos: sí/ no \\
\hline Apariencia $^{3}$ & Valoración & Puntuación de 1 a 10 \\
\hline Diferenciación & Observación & Sí/ no/ qué elementos \\
\hline Velocidad & Observación & Sí/ no \\
\hline \multirow{4}{*}{ Accesibilidad $^{4}$} & Muy accesible & De 0 a 10 problemas \\
\hline & Bastante accesible & De 11 a 30 problemas \\
\hline & Poco accesible & De 31 a 90 problemas \\
\hline & Insuficientemente accesible & Más de 90 problemas \\
\hline \multirow{5}{*}{ Utilidad $^{5}$} & Familias $^{1}$ & Puntuación de 1 a 10 \\
\hline & Alumnado & Puntuación de 1 a 10 \\
\hline & Profesorado & Puntuación de 1 a 10 \\
\hline & Personal de centro & Puntuación de 1 a 10 \\
\hline & Otros usuarios & Puntuación de 1 a 10 \\
\hline
\end{tabular}

Notas: ${ }^{1}$ En el apartado de Contenido nos encontramos con el subapartado Historia y Metas que se valora de 0 a 3 . En este sentido se valora en ambas con un "o" a aquellos sitios web que no tienen referencia alguna a la historia y metas; con un "1" a los que tienen alguna referencia de carácter leve; con un "2" a los que tienen referencias de extensión introductoria pero que no se adentran en detalles; con un "3" a los que tienen una información completa y actualizada del subapartado en cuestión. ${ }^{2}$ En el apartado de Contenido nos encontramos con los subapartado Proyectos y planes donde se valoran de 0 a 3 el PEC, el PGA y el NOFC, respectivamente. En este sentido se valora en ambas con un "O" a aquellos sitios web que no tienen información sobre estos aspectos; con un " 1 " a los que tienen alguna referencia de carácter leve; con un " 2 " a los que tienen referencias de extensión introductoria pero que no se adentran en detalles; con un " 3 " a los que tienen una información completa y actualizada del subapartado en cuestión. ${ }^{3}$ En el apartado de Apariencia existe una valoración de 1 a 10 , la cual obedece a los siguientes parámetros. ${ }^{4}$ En el apartado de Accesibilidad se analizan los distintos sitios a través de la página de análisis online de accesibilidad web "http://www.tawdis.net“. Esta web pertenece a la "Fundación CTIC" que es la sede de la oficina española de W3C y es una de las entidades con mayor número de investigadores en este aspecto. Su herramienta de análisis mide que la web sea perceptible, operable, comprensible y robusta e indica el número de problemas que encuentra en cada uno de estos criterios. Esto servirá para clasificar a las webs en "muy accesibles" (cuando se detecte de 0 a 10 problemas en total entre todos los criterios), "bastante accesibles" (de 11 a 30), "poco accesibles" (de 31 a 90) e "insuficientemente accesibles" (cuando sean más de 90). Para analizar los datos se ha realizado un análisis estadístico descriptivo de recuento de frecuencias que han sido traducidas a términos de porcentajes, habiéndose categorizado también informaciones cualitativas relevantes durante el estudio de algunas de las variables. ${ }^{5}$ En el apartado de Utilidad existe una valoración de 1 a 10 para la utilidad de las páginas web para las distintas partes educativas (públicos) a los que se dirigen las páginas web. Esta valoración obedece a los siguientes parámetros para cada una de las partes.

Fuente: Elaboración propia.

\section{Resultados}

A continuación, recogemos los principales resultados obtenidos tras el análisis de las páginas webs de los centros objeto de estudio. Nos detendremos a examinar los ocho aspectos anteriormente señalados: contenido, organización, navegación, apariencia, diferenciación, velocidad, accesibilidad y utilidad (cuadro 2). 
Cuadro 2. Resultados obtenidos tras el análisis de las páginas web

\begin{tabular}{|c|c|c|c|c|}
\hline 1 & 2 & 3 & 4 & 5 \\
\hline $\begin{array}{l}\text { La web provoca } \\
\text { un rechazo } \\
\text { absoluto } \\
\text { (incoherencia } \\
\text { visual, } \\
\text { contrastes de } \\
\text { colores, } \\
\text { agotamiento } \\
\text { visual...). No } \\
\text { contiene } \\
\text { elementos } \\
\text { gráficos de } \\
\text { calidad. }\end{array}$ & $\begin{array}{l}\text { La web es } \\
\text { incoherente } \\
\text { visualmente, } \\
\text { pero contiene } \\
\text { uno o dos } \\
\text { elementos de } \\
\text { diseño con algo } \\
\text { de rigor } \\
\text { (imágenes, } \\
\text { textos...). }\end{array}$ & $\begin{array}{l}\text { Existen algunos } \\
\text { elementos de } \\
\text { coherencia visual } \\
\text { (tamaño, } \\
\text { contraste colores, } \\
\text { justificación...) } \\
\text { pero aún } \\
\text { insuficientes } \\
\text { como para } \\
\text { provocar } \\
\text { atracción. }\end{array}$ & $\begin{array}{l}\text { Se cuida la } \\
\text { apariencia gráfica } \\
\text { moderadamente, } \\
\text { pero no en la } \\
\text { totalidad de } \\
\text { apartados y sub- } \\
\text { apartados de la } \\
\text { sede web. }\end{array}$ & $\begin{array}{l}\text { Se cumple el } \\
\text { requisito } 4, \\
\text { pero en la } \\
\text { totalidad de los } \\
\text { apartados y } \\
\text { sub-apartados. }\end{array}$ \\
\hline 6 & 7 & 8 & 9 & 10 \\
\hline $\begin{array}{l}\text { La web tiene } \\
\text { coherencia } \\
\text { visual y una } \\
\text { calidad en el } \\
\text { diseño } \\
\text { aceptable de } \\
\text { manera global. }\end{array}$ & $\begin{array}{l}\text { Se percibe un } \\
\text { gusto gráfico y } \\
\text { de diseño } \\
\text { notable, más } \\
\text { que aceptable. }\end{array}$ & $\begin{array}{l}\text { La atracción } \\
\text { hacia la web para } \\
\text { el visitante en } \\
\text { criterios de } \\
\text { calidad, gusto y } \\
\text { apariencia es } \\
\text { total. }\end{array}$ & $\begin{array}{l}\text { Cumple el } \\
\text { requisito } 8 . \\
\text { Está a la } \\
\text { vanguardia. } \\
\text { Utiliza patrones } \\
\text { de moda en el } \\
\text { mundo del diseño } \\
\text { gráfico (fuentes, } \\
\text { imágenes, etc.). }\end{array}$ & $\begin{array}{l}\text { Cumple los } \\
\text { requisitos } 8 \text { y } \\
9 . \\
\text { Existe una } \\
\text { integración } \\
\text { total entre el } \\
\text { diseño de la } \\
\text { página web y el } \\
\text { diseño del } \\
\text { propio centro } \\
\text { físico. Una } \\
\text { única política } \\
\text { de imagen. }\end{array}$ \\
\hline 1 & 2 & 3 & 4 & 5 \\
\hline $\begin{array}{l}\text { No se } \\
\text { contempla } \\
\text { ningún } \\
\text { elemento de } \\
\text { utilidad para la } \\
\text { parte. }\end{array}$ & $\begin{array}{l}\text { Existe } \\
\text { información de } \\
\text { carácter } \\
\text { genérico que es } \\
\text { de poca utilidad } \\
\text { para la parte. }\end{array}$ & $\begin{array}{l}\text { Existe } \\
\text { información de } \\
\text { carácter genérico } \\
\text { que es de escasa } \\
\text { utilidad para la } \\
\text { parte. }\end{array}$ & $\begin{array}{l}\text { Existe } \\
\text { información de } \\
\text { carácter genérico } \\
\text { que es de cierta } \\
\text { utilidad para la } \\
\text { parte, pero aún } \\
\text { insuficiente. }\end{array}$ & $\begin{array}{l}\text { Contiene } \\
\text { información de } \\
\text { utilidad para la } \\
\text { parte (horarios, } \\
\text { contacto, etc.). }\end{array}$ \\
\hline 6 & 7 & 8 & 9 & 10 \\
\hline $\begin{array}{l}\text { Cumple el } \\
\text { requisito } 5 . \\
\text { Fomenta la } \\
\text { participación de } \\
\text { la parte de } \\
\text { alguna manera } \\
\text { con } \\
\text { herramientas } \\
\text { genéricas. }\end{array}$ & $\begin{array}{l}\text { Cumple el } \\
\text { requisito } 5 \text { y } 6 . \\
\text { La herramienta } \\
\text { de participación } \\
\text { es dinámica y es } \\
\text { atendida por un } \\
\text { soporte que no } \\
\text { cae en la } \\
\text { obsolescencia. }\end{array}$ & $\begin{array}{l}\text { Cumple el } \\
\text { requisito } 5,6 \text { y } 7 . \\
\text { Contiene otras } \\
\text { herramientas } \\
\text { online de } \\
\text { comunicación } \\
\text { externas a la web } \\
\text { y de utilidad para } \\
\text { la parte (redes } \\
\text { sociales...). }\end{array}$ & $\begin{array}{l}\text { Cumple el } \\
\text { requisito } 5,6,7 \text { y } \\
8 . \\
\text { Fomenta a la } \\
\text { parte para la } \\
\text { creación de } \\
\text { contenido web. }\end{array}$ & $\begin{array}{l}\text { Cumple los } \\
\text { requisitos } 5,6, \\
7,8 \text { y } 9 . \\
\text { Contiene } \\
\text { plataformas } \\
\text { creadas ex } \\
\text { profeso para la } \\
\text { dinamización e } \\
\text { interacción de } \\
\text { la parte en } \\
\text { relación al } \\
\text { centro y al } \\
\text { mundo } \\
\text { educativo. }\end{array}$ \\
\hline
\end{tabular}

Fuente: Elaboración propia. 


\subsection{Contenido}

Para analizar el contenido hemos analizado si contiene y cómo utiliza: datos de contacto (correo, dirección, teléfono, redes sociales y blogs); galería de fotos (de instalaciones, día a día, excursiones, otras actividades y eventos); historia y metas; documentos administrativos (comunicados y/o avisos, impresos, horarios conserjería y secretaría, matriculación); información de interés (AMPA, transportes, otra información local-global); proyectos y planes (PEC, PGA, NOFC, otros); enseñanzas, profesorado y departamentos; y servicios y actividades (horario centro, horario clases, calendario escolar, biblioteca, noticias, actividades). Se trata de un apartado más amplio que el resto, ya que para valorar el contenido se precisaba analizar muchos aspectos.

\subsubsection{Datos de contacto}

Un 93' $75 \%$ de los centros ponen a disposición del usuario su "correo electrónico". Un único centro no informa sobre su contacto en este sentido, y dos centros permiten contactar a través de un formulario web, sin mostrar su correo de centro. En cuanto a la "dirección postal" y su "localización" a través de mapa del entorno, el 89,58\% sí las exponen. Tan sólo un centro no tiene información de ningún tipo sobre esto, y cuatro centros sí que informan de su dirección postal pero no de su localización y ubicación vía mapa. Casi la totalidad de los centros informan de su "teléfono" en las sedes webs (el 97'92\%). Únicamente un centro no dispone de este dato de contacto en su página.

$\mathrm{El}$ análisis de las "redes sociales y blogs" arroja varios datos interesantes. El 87'5\% de las páginas webs tienen enlaces directos a algún tipo de red social o blog, y el 12'5\% no. De los centros que usan redes sociales, "Facebook" es la favorita y supone un 35 ' $72 \%$ de uso en relación a éstas, seguida por "Twitter" con un 28 ' $57 \%$. Por otra parte, existe un uso del $35^{\prime} 71 \%$ de otro tipo de redes sociales. En cuanto a los blogs (de centro, de departamento, biblioteca, etc.) y enlaces a estos en las páginas web de centro, existe un total de 334 (55’69\% están activos, mientras que el 44’31\% aparecen inactivos u obsoletos) (figura 1).

\subsubsection{Galería de fotos}

La tipología de las fotografías de la galería había sido establecida en las instantáneas sobre "instalaciones" (el 72'92\% de los centros sí disponen de este tipo de fotos en sus sedes web), sobre el "día a día” del centro (el 72’92\% de los centros sí); sobre "salidas escolares" 81’25\% sí; y, por último, sobre otras “actividades y eventos” el 83’33\% sí (figura 1).

\subsubsection{Historia/metas}

En relación a la "historia", el 64’58\% de los centros no explica la evolución del centro. Teniendo como referencia de valoración el “3” como que la página web dispone de información completa de estos dos epígrafes, y a la baja en valoración hasta puntuar con un " 0 " a las sedes web que no tengan nada de información sobre ello (siguiendo los parámetros de valoración, por tanto, expuestos en la metodología); valoramos al 2'08\% con una puntuación de "1"; el 6’25\% con un “2”; y, por último, con una valoración máxima de “'”, el 27'09\% de los centros (figura 2). 


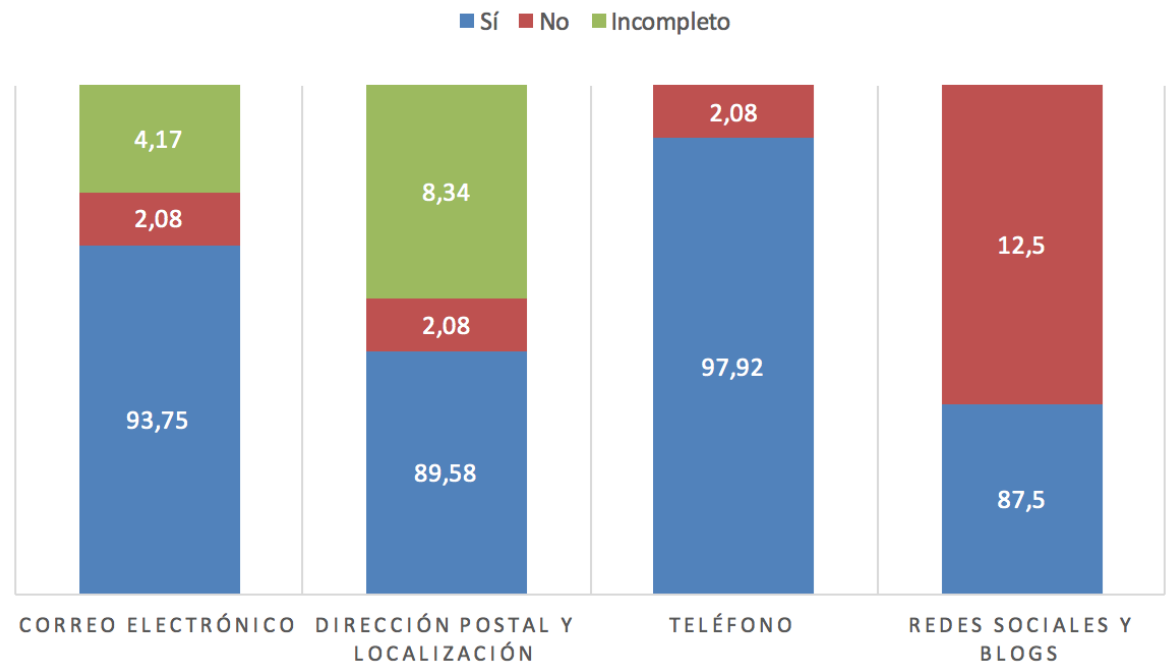

Figura 1. Datos de contacto de los centros

Fuente: Elaboración propia.

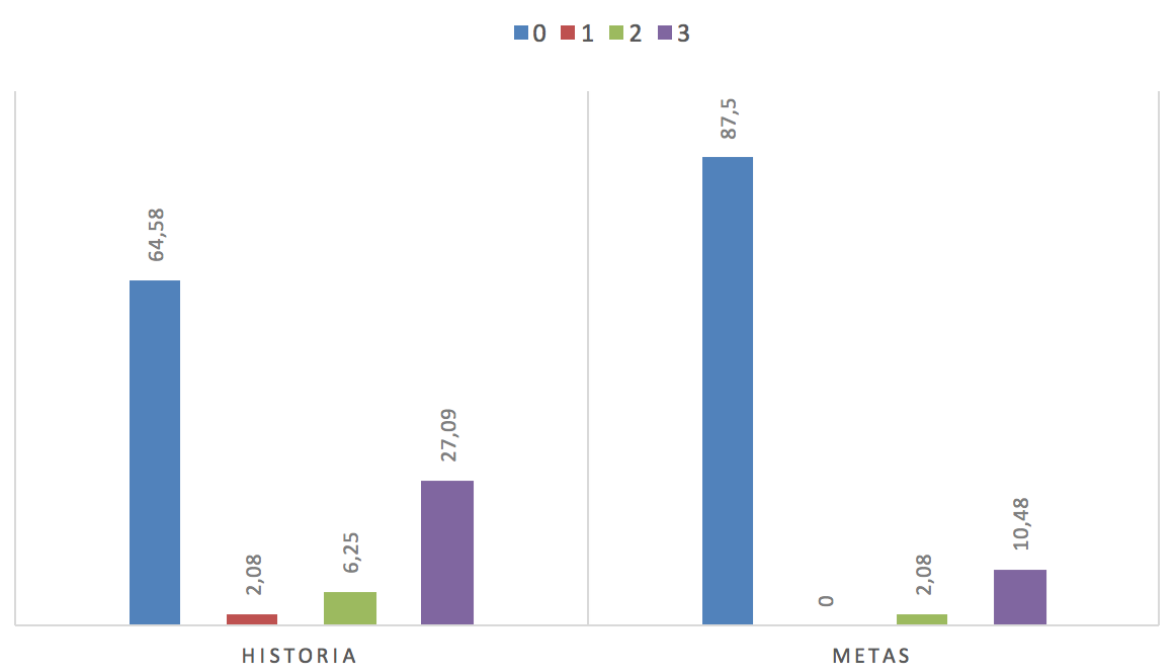

Figura 2. Valoración historia/ metas Fuente: Elaboración propia.

En lo relativo a las "metas institucionales", un 87 ' $5 \%$ de los centros no las mencionan y han obtenido una valoración de "1"; un 2'08\% una valoración de "2"; y únicamente el 10 '42\% menciona las metas íntegramente con un “3” de valoración.

\subsubsection{Documentos administrativos}

En relación a la parte administrativa, un $66^{\prime} 67 \%$ dispone de una sección de "comunicados/avisos", un 31'25\% no y un centro muestra esta sección de manera incompleta. En cuanto a "impresos" varios, propios del centro y de la secretaría, un 60’42\% sí dispone de ellos de forma completa, un 33'33\% no, y un 6’25\% tiene algunos. Lo mismo ocurre con la información y documentación sobre la "matriculación": un 62' $5 \%$ ofrece esto a los usuarios en sus sedes web, un $355^{\prime} 42 \%$ no, y un 2'08\% de manera incompleta. Los "horarios de secretaría/ conserjería” están en un 64 '58\% de los casos. 


\subsubsection{Información de interés}

El 56’25\% tiene información sobre el AMPA del centro; el resto, no. La “información sobre transporte" se ve reflejada en menor escala en las webs (22'92\%). En cuanto a "otro tipo de información" un 54'17\% expone algo, y el resto no.

\subsubsection{Proyectos y planes}

Para valorar la calidad de la exposición de estos apartados, se había establecido una puntuación de "O a 3" (siendo "O" sinónimo de una inexistencia sobre tal proyecto o plan, y "3" una completa información sobre el mismo; siguiendo los parámetros de valoración expuestos en la metodología) (figura 3).

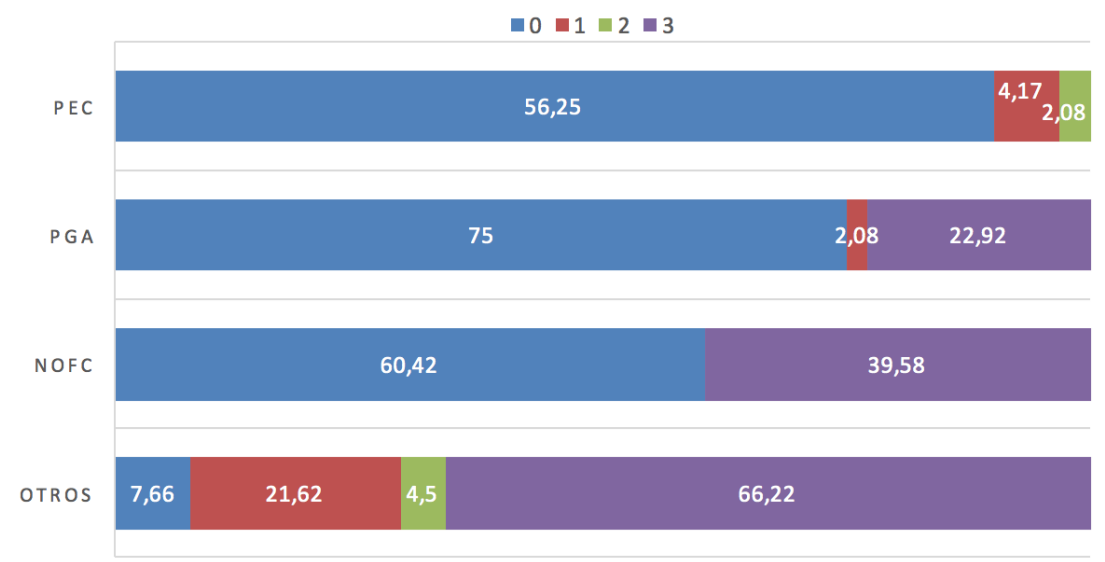

Figura 3. Valoración proyectos y planes

Fuente: Elaboración propia.

\subsubsection{Enseñanzas, profesorado y departamentos}

Existe información sobre las enseñanzas que se imparten en el centro a todos los niveles en la amplia mayoría de los centros (un $85^{\prime} 42 \%$ ). Únicamente un $14{ }^{\prime} 58 \%$ no muestran esta información. En lo relativo al "profesorado", existe un 62'5\% de las webs que nos hablan del profesorado del centro, y un 37 ' $5 \%$ que no exponen nada al respecto. Y ya, por último, la información sobre los "departamentos" (su estructura, profesores, jefe de departamento, etc.), un $75 \%$ sí que nos informan sobre ello.

\subsubsection{Servicios y actividades}

La información sobre servicios y actividades que se nos muestra en las páginas web de los centros se distribuye de la siguiente manera. En relación a los "horarios de centro" se refleja en el $50 \%$ de las páginas. Por otra parte, los "horarios de las clases" nos lo ofrecen el 41'67\%. En relación al “calendario escolar”, obtenemos los mismos porcentajes (41'67\% sí y $58^{\prime} 33 \%$ que no). Las webs que mencionan el servicio de "biblioteca" de centro representan un $66^{\prime} 67 \%$. Un alto porcentaje (el $899^{\prime} 58 \%$ ) tiene un apartado de "noticias" sobre el centro. La información sobre las "actividades" de centro están incluidas en el $83^{\prime} 33 \%$ de las webs.

\subsubsection{Actualización}

Un $75 \%$ mantiene su página actualizada; mientras que un $1458 \%$ no, teniéndolas obsoletas; y un $10 \% 2 \%$ las mantienen actualizadas aparentemente. 


\subsection{Organización y navegación}

Disponen de "botonera vertical" el $4792 \%$ de las páginas y "botonera horizontal" la inmensa mayoría (el 89'58\%). Uno de los elementos más importantes de navegación, el "mapa web", es utilizado por el 56 '25\%. En los "enlaces directos" a otros sitios web de interés, destaca que casi todos lo utilizan (91'67\%), únicamente cuatro páginas no utilizan (el 8’33\%) (figura 4).

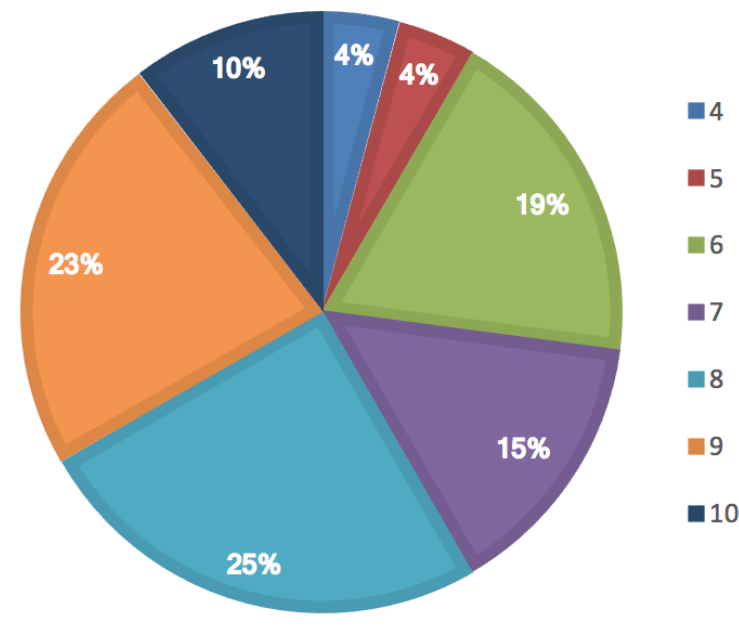

Figura 4. Valoración organización y navegación Fuente: Elaboración propia.

\subsection{Apariencia}

Se estableció una puntuación de "1 a 10" para valorar la calidad gráfica según los parámetros estipulados en la metodología, apoyados por el marco teórico. Con los resultados se obtiene una media de 7,37 (figura 5).

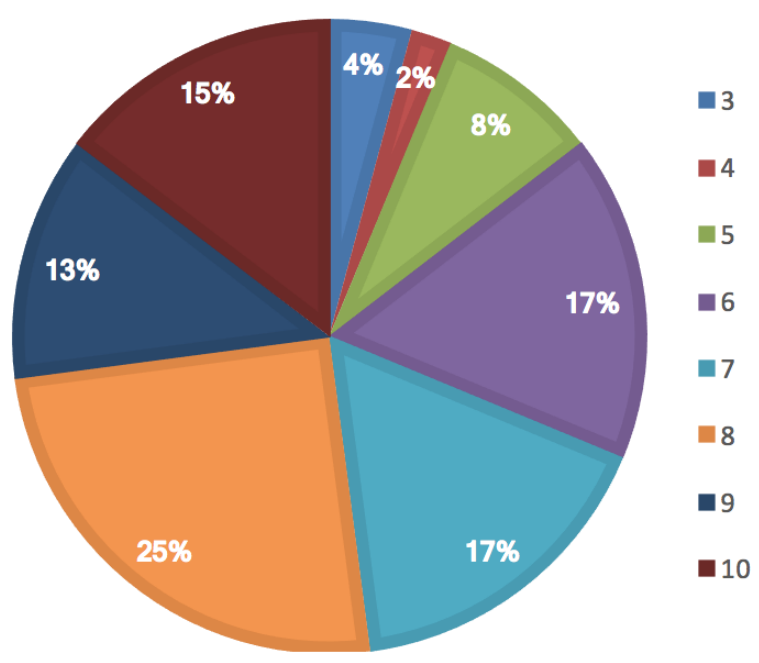

Figura 5. Valoración apariencia Fuente: Elaboración propia. 


\subsection{Diferenciación}

Emplean estrategias de marketing el 18 ' $75 \%$ de las webs (9 centros). Los elementos empleados son: utilización de lenguaje de marca, posicionamiento educativo idílico en el discurso, o uso de fotografías y vídeos corporativos basados en cánones estéticos. No se ha encontrado ningún tipo de comunicación de imagen de centro en lemas o tipo folleto publicitario, únicamente nos hemos encontrado con los logotipos, pero no en un sentido mercadotécnico. Como han sido pocas las webs que han hablado de su filosofía, tampoco se ha advertido discursos de posicionamiento ante la diversidad.

\subsection{Velocidad}

La velocidad de las páginas web no presenta deficiencias en su navegación ni en la descarga de sus documentos o conexión en alguno de los enlaces externos. Las 48 sedes web muestran una respuesta óptima en este aspecto.

\subsection{Accesibilidad}

Después de examinar todas las páginas web en la página de análisis online de accesibilidad "http://www.tawdis.net" según las "Pautas de Accesibilidad al contenido Web (WCAG 2.0)" de la "Iniciativa de Accesibilidad a la Web, el World Wide Web Consortium)", obtenemos:

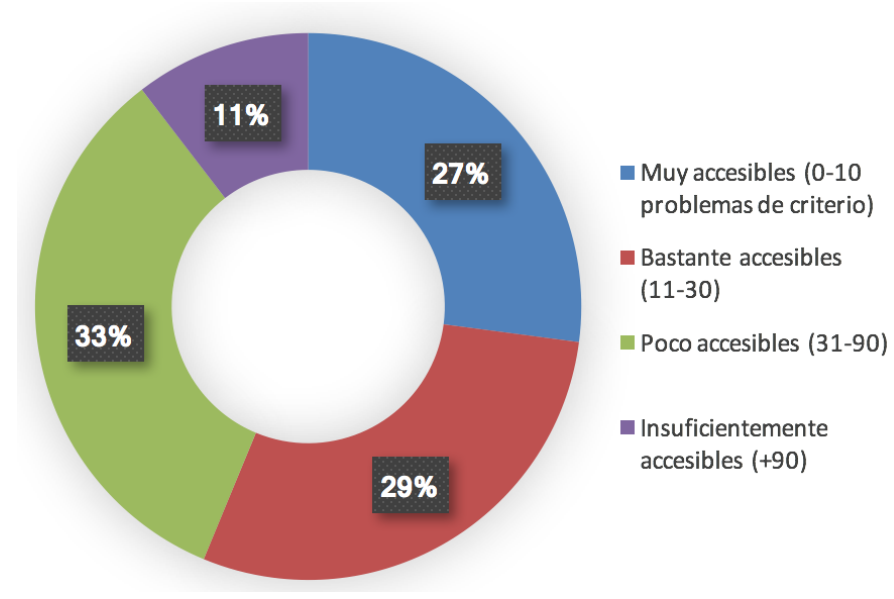

Figura 6. Accesibilidad Webs

Fuente: Elaboración propia.

Encontramos en este apartado 27 sitios web "muy o bastante accesibles". Por su parte, 21 "poco o insuficientemente accesibles".

\subsection{Utilidad}

Hemos analizado el grado de utilidad que las páginas desempeñan para las partes interesadas (familias, alumnado, profesorado, personal de centro y otros usuarios), así como, la utilización de recursos u otros elementos de enseñanza y aprendizaje entre profesorado y alumnado. De esta manera, se han valorado las páginas según el grado de utilidad para los distintos públicos de interés con una medición de "1 a 10" según los parámetros de valoración que se expusieron en la metodología.

En la mayoría de las páginas webs, las familias pueden contactar con el centro e informarse sobre distintos aspectos de su interés (académicos, administrativos, horarios, profesores, 
etc.); el alumnado puede acceder a lugares donde prolongar sus conocimientos, o donde aprender de manera continua, así como, horarios, etc.; el profesorado tiene a su disposición posibilidades para subir todas las pesquisas de sus materias, así como, otro material de refuerzo y aprendizaje educativo; y el resto de visitantes puede informarse y hacerse una idea de lo que son los centros, de lo que disponen y de cómo se gestionan (figura 7).

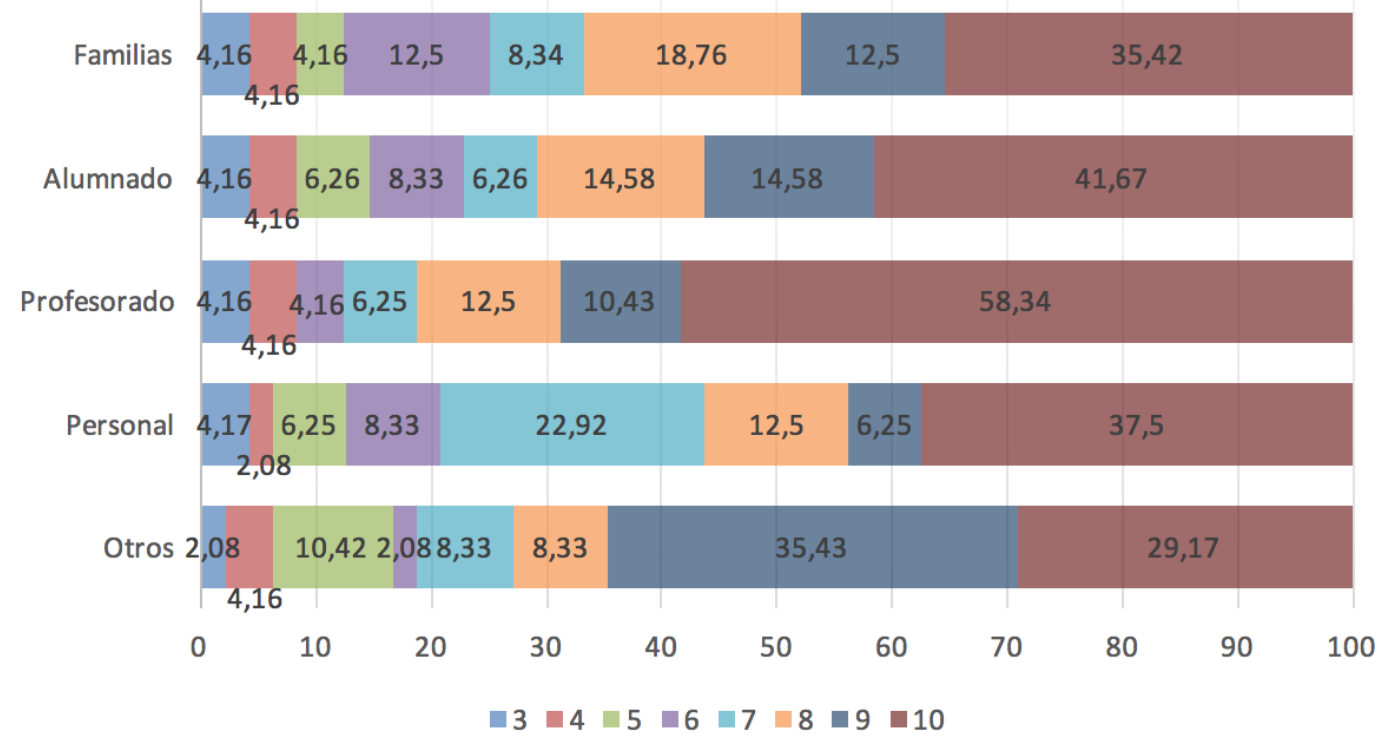

Figura 7. Valoración utilidad páginas web para las partes interesadas Fuente: Elaboración propia.

Con este resultado, se obtiene una nota media para las "familias" de "8", para el "alumnado" de "8,1", para el "profesorado" de "8,7", para el "personal de centro" de "7,94", y para "otros usuarios" de " 8,23 ".

\section{Discusión y conclusiones}

En conclusión, nos encontramos con un panorama alentador en el terreno de las páginas web de los IES públicos de Cantabria. Se tiende hacia sitios webs "progresivos, activos e interactivos", en detrimento de las sedes web "emergentes y pasivas" (Hu y Soong, 2007; Taddeo y Barnes, 2016; Wells, 2001) que son minoría en la región. Esto contradice la hipótesis de partida que teníamos, y nos encontramos con que las páginas web visitadas no cumplen únicamente una función informativa.

Las sedes web muestran en líneas generales un contenido bastante completo y actualizado que introduce a los centros a modo de presentación. Facilitando datos de contacto y ubicación, galería de imágenes, documentos administrativos, información sobre enseñanzas, profesorado y departamentos. Y de una manera satisfactoria, tanto para las audiencias internas (personal del centro, familias y alumnado), como para las audiencias externas (profesionales potenciales y sociedad en general) (Du Preez, 2007). Aspectos a mejorar en el contenido sería una inclusión por parte de los centros de su historia y metas (pues actualmente son pocos los que hablan de ello); un mayor suministro de datos útiles de interés y una mejora de la calidad de los mismos; una mayor exposición de los planes y proyectos principales que muestren el "alma" del centro; y aunque sí se detecta una apuesta 
por las noticias y eventos de los centros, se tendría que incluir en más centros todavía otras informaciones de las actividades y servicios que se ofrecen (calendario escolar, biblioteca, etc.).

En relación a la organización y facilidad de navegación, se echa de menos una mayor apuesta por un elemento como es el mapa de navegación, pero la valoración global es notable. Valoración también de esta calidad, para el diseño y apariencia gráfica general de las páginas analizadas, el cual es el único signo apreciable de diferenciación (entendiéndolo como marketing escolar) que se encuentra en la mayoría de las webs, ya que éste no está inmerso, ni se palpa en el estudio desde una perspectiva comercial. A la accesibilidad aún le queda recorrido y se ha de seguir trabajando en ello, y desde la administración se ha de hacer ver a los centros la necesidad de su aplicación (aunque es un asunto en alza y con una cifra aceptable de sitios web accesibles). Todas estas cuestiones son básicas en la gestión del estilo web (Lynch, Horton y Marcotte, 2016).

En el aspecto de utilidad para las partes, la mayoría las páginas web están orientadas a las partes interesadas al contrario de lo que planteamos en nuestra hipótesis. Existe un desarrollo creciente de las páginas dentro de su uso como soporte de interacción con sus usuarios, así como, plataforma de aprendizaje-enseñanza y fuente de recursos de todo tipo. De esta manera, a las sedes web en lugares donde crear una identidad conjunta entre los centros y las partes interesadas (Du Preez, 2007; Hartshorne et al., 2006, 2008; Maddux, 2001; Taddeo y Barnes, 2016;). Se echa de menos la publicación de trabajos de estudiantes, que no se han encontrado y lo cual tiene un gran potencial como indican los teóricos (Associates, Jacob y Jensen, 2012; Özkanb, Altun y Uimúekd, 2009).

Aunque todavía queda trabajo, una gran parte de los centros han comprendido la audiencia de sus sedes web, y ello les ha ayudado a tomar buenas decisiones sobre cómo debe ser organizada como ya indicaran Regan (2003), Maddux (2001) y Du Preez (2007). Esto conduce hacia páginas de calidad que han optimizado las operaciones organizacionales y funcionales de su centro, como ya dijera Tubin y Klein (2007).

Una de las grandes limitaciones del presente estudio ha sido el análisis de la dimensión velocidad. No se han encontrado problemas de velocidad, pero para realizar el trabajo de campo se ha utilizado un único medio informático, por lo que la información sobre esta dimensión está sesgada. En futuros estudios recomendamos realizar un análisis de los sitios web desde diferentes ordenadores para valorar mejor este aspecto.

En relación a futuros investigadores sobre la materia, se invita a analizar el papel que desempeña el "Coordinador TIC" de centro como desarrollador del sitio web y como soporte del mismo (Álvarez, 2017; Álvarez y García, 2017). Existen numerosos estudios sobre sus funciones e importancia, pero no investigaciones únicas sobre su función ligada a este aspecto. También, otra dimensión en la que se pueden adentrar los investigadores, es la dimensión "accesibilidad”, cuyo campo de investigación tiene un gran potencial según hemos apreciado durante la investigación. Por último, es muy interesante considerar en futuros estudios la utilización que hacen los centros educativos de las nuevas redes sociales (Facebook, Twitter, Instagram...), pues durante el análisis se ha distinguido un uso creciente de las mismas. Asimismo, fomentar modos de uso de éstas con una misión pedagógica y de gestión de centro. Asimismo, sería interesante replicar el estudio en otras comunidades autónomas para aumentar el conocimiento más allá de la comunidad de Cantabria. Sería un reto de futuro llegar a formular una normativa aplicable a los centros 
de Educación Secundaria que les permitiese diseñar, desarrollar e innovar su web escolar atendiendo a todos los criterios examinados en este artículo.

Por todo ello, concluimos con las palabras de Ferrer (2005): "es tan irracional menospreciar las posibilidades que nos brinda la red y limitamos a hacer un uso transmisor, como emplear un avión a reacción para trasladarse por carretera sin llegar a despegar ni un solo palmo del suelo" (p. 209). Con este trabajo esperamos alentar a la mejora a los futuros profesionales que trabajen en el mundo de las páginas web escolares $\mathrm{y}$ apuesten por su mejora.

\section{Referencias}

Álvarez, C. (2017). ¿Qué me ofrecen las páginas web de los centros educativos? Estudio exploratorio en Cantabria (España). REICE. Revista Iberoamericana sobre Calidad, Eficacia y Cambio en Educación, 15(3), 49-63. https://doi.org/10.15366/reice2017.15.3.003

Álvarez, C. y García, J. I. (2017). The management of schools' websites in Cantabria, Spain. Research in Learning Technology, 25(1), 70-79. https://doi.org/10.1080/21567069.2017.1270579

Aguilar, M. C. y Leiva, J. J. (2012). La participación de las familias en las escuelas TIC: Análisis y reflexiones educativas. Revista de Medios y Comunicación, 40, 7-19.

Associates, T. S., Jacob, A. M. y Jensen, L. I. (2012). School site visits: What can we learn from choice schools in Milwaukee? A Fayetteville, AR: University of Arkansas.

Balas, E., Mirea, D. y Mirea, L. (2014). The ICT coordinator in school a XXI century education. Journal Plus Education, 10(1), 312-317.

Bodura, E., Özkanb, F., Altun, E. y Ùimúekd, Ö. (2009). The role of teacher in web enhanced learning activities in primary school information technologies lesson: A case study. Procedia-Social and Behavioral Sciences, 1(1), 1043-1051. https://doi.org/10.1016/j.sbspro.2009.01.188

Camps, V. J., Sanz, M. J., García, C., Caballero, M. T. y Fernández, D. (2015, enero). La importancia del diseño de una página web de un departamento. Comunicación presentada en las XIII Jornadas de redes de investigación en docencia universitaria: Nuevas estrategias organizativas y metodológicas en la formación universitaria para responder a la necesidad de adaptación y cambio. Universidad de Alicante.

Careaga, M., Jiménez, L. y Badilla, M. G. (2014). School networks to promote ICT competences among teachers. Case study in intercultural schools. Computers in Human Behavior, 30, 442451. https://doi.org/10.1016/j.chb.2013.06.024

Castells, M. (2006). La sociedad red. Madrid: Alianza Editorial.

Du Preez, H. (2007). Issues to consider during the development and promotion of a primary school web site. Pretoria: University of Pretoria.

Ferrer, R. (2005). Diseño de páginas web en educación. Tendencias Pedagógicas, 10, 199-220.

Hartshorne, R., Friedman, A., Algozzine, B. y Isibor, T. (2006). Secondary schools online: Are high school web sites effective? American Secondary Education, 34(2) 50-66.

Hartshorne, R., Friedman, A., Algozzine, B. y Kaur, D. (2008). Analysis of elementary school web sites. Technology E Society, 11(1), 291-303. 
Hu, C. y Soong, A. K. (2007). Beyond electronic brochures: An analysis of Singapore primary school web sites. Educational Media International, 44(1), 33-42. https://doi.org/10.1080/09523980600922761

Krach, S. K. y Jelenic, M. (2009). The other technological divide: K-12 web accessibility. Journal of Special Education Technology, 24(2), 31-37. https://doi.org/10.1177/016264340902400203

Maddux, C. D. (2001). Solving accessibility and other problems in school and classroom web sites. $\begin{array}{lll}\text { Rural Special Education } & \text { Quarterly, } & \text { 20(4), }\end{array}$ https://doi.org/10.1177/875687050102000403

McGarr, O. y McDonagh, A. (2013). Examining the role of the ICT coordinator in Irish postprimary schools. Technology, Pedagogy and Education, 22(2), 267-282. https://doi.org/10.1080/1475939X.2012.755132

Méndez, J. M. y García, M. D. (2016). Las TIC en centros de educación primaria y secundaria de Andalucía. Un estudio de casos a partir de buenas prácticas. Digital Education Review, 29, 34-65.

Moreira, J. A., Reis-Monteiro, A. y Machado, A. (2017). E-innovación en la educación superior. Comunicar, 51(21), 39-49.

Ng, C. K., Parette, P. y Sterrett, J. (2003). Evaluation of a graduate school web-site by graduate assistants. College Student Journal, 37(2), 242-260.

Oyola, C. X. (2016). Análisis de calidad de los sitios webs de las universidades del Ecuador mediante herramientas y estándares Web. Tesis de Doctorado. Universidad Técnica de Machala, Ecuador.

Peña, S., Lazkano, I. y García, D. (2016). Internet del futuro. Comunicar, 46(24), 29-36.

Poock, M. (2005). Determining the design of effective graduate school web sites. College and University Journal, 80(3), 23-26.

Regan, B. (2003). Usability in school web sites: Five steps to a better web site for your school. Library Media Connection, 21(4), 71-98.

Rodríguez, F. P., Pozuelos, F. J. y León, J. C. (2014). The role of ICT coordinator. Priority and time dedicated to professional functions. Computers \& Education, 72, 262-270. https://doi.org/10.1016/j.compedu.2013.11.009

Rodríguez, G., Laitano, M. I. y Andrés, G. (2013). Análisis propositivos para la construcción de entornos web accesibles en educación superior. Revista IRICE, 5, 11-35.

Romero, R., Gallego, O., Noguera, M., Romero, D. y Torres, M. L. (2002). Diseño, aplicación y evaluación de un tutorial para elaborar páginas web educativas. Revista de Enseñanza Universitaria, 19, 185-195.

Smith, A. (2007). Adam smith meets walt disney: School image on the world wide web. Journal of Educational Administration and History, 39(1), 63-80. https://doi.org/10.1080/00220620701194325

Stilz, J. y Menter, L. (2009). Inaccessible school webpages: Are remedies available? Journal of Law E Education, 38(3), 393-408.

Taddeo, C. y Barnes, A. (2016). The school website: Facilitating communication engagement and learning. British Journal of Educational Technology, 47(2), 421-436. https://doi.org/10.1111/bjet.12229 
Tamatea, L., Hardy, J. y Ninnes, P. (2008). Paradoxical inscriptions of global subjects: Critical discourse analysis of international schools' websites in the Asia. Critical Studies in Education, 49(2), 157-170. https://doi.org/10.1080/17508480802040241

Tubin, D. y Klein, S. (2007). Designing a school website: Contents, structure, and responsiveness. Planning and Changing, 38(4), 191-207.

Wells, A. (2001). Creating and maintaining the school web site, meaningless task or educational activity, luxury or necessity? En M. Leask (Ed.), Issues in teaching using ICT (pp. 130-142). Nueva York, NY: Routledge Falmer.

Wells, J. A. y Barron, A. E. (2006). School web sites: Are they accessible to all? Journal of Special Education Technology, 21(3), 23-30. https://doi.org/10.1177/016264340602100303

Wilson, T. S. y Carlsen, R. L. (2016). School marketing as a sorting mechanism: A critical discourse analysis of charter school websites. Peabody Journal of Education, 91, 24-46. https://doi.org/10.1080/0161956X.2016.1119564

Yemini, M. y Cohen, A. (2016). School websites as an internationalization assessment tool. Education and Information Technologies, 21(3), 607-623. https://doi.org/10.1007/s10639014-9343-7

\section{Breve CV de los autores}

\section{Víctor Tardío-Crespo}

Máster en Formación del Profesorado de Secundaria y FP por la Universidad de Cantabria (2017), licenciado en Publicidad y Relaciones Públicas por la Universidad del País Vasco (2007). Ha desarrollado la mayor parte de su carrera profesional en el mundo de la comunicación (ejecutivo de cuentas en varias agencias de publicidad, ejecutivo de cuentas freelance para Onda Cero Cantabria y el grupo Atresmedia, community manager y gestor cultural del Centro Cultural Ramón Pelayo de Medio Cudeyo, etc.). Su línea de investigación principal es el análisis de la gestión de las redes web en el ámbito escolar en Educación Secundaria. ORCID ID: https://orcid.org/0000-0002-0224-2025. Email: vtardiocrespo@gmail.com

\section{Carmen Álvarez-Álvarez}

Doctora en Pedagogía (Premio Extraordinario de Doctorado) por la Universidad de Oviedo, Máster en Acción Tutorial por la Universidad de Valencia, licenciada en Pedagogía y Graduada en Educación Primaria. Profesora Ayudante Doctor del Departamento de Educación de la Universidad de Cantabria en el área de Didáctica y Organización Escolar. Es miembro fundador de la Red Iberoamericana de Investigadores en el estudio de la educación en territorios rurales de la Asociación Universitaria iberoamericana de Postgrado. Ha participado en numerosos congresos a nivel nacional e internacional, ha realizado diversas estancias de investigación y ha publicado en prestigiosas revistas. Su línea de investigación principal es la Organización Escolar en Educación Primaria y Secundaria. ORCID ID: https://orcid.org/0000-0002-8160-2286. Email:mcalvarezalvarez@gmail.com 